\title{
Fire Research in China
}

\section{FAN WEICHENG}

State Key Laboratory of Fire Science

University of Science and Technology of China

Hefei, Anhui 230026, P. R. China

\section{SHUFEN}

National Science Foundation of China

Beiling 100083, P. R. China

\begin{abstract}
Fire losses are continuously increasing in China, there is an urgent need to enhance fire research so as to mitigate fire damage with moderate costs.

A system of fire research consisting of basic research, applied research and development of new technology for fire prevention and protection is being formed in China. A general structure of organizations related to fire research is outlined, and several main institutions of fire research are introduced. Typical research work in the State Key Lab of Fire Science is given as an example of fire research in China.
\end{abstract}

\section{INTRODUCTION}

\section{Rapid Increase of Fire Losses.}

Fire losses in China have increased rapidly in resent years. A fire statistics with exclusive of forest fire is given in Table 1, and direct fire losses are shown in Fig. 1. It should be pointed out that the fire loss refers only the direct property loss (DPL). Neither indirect losses such as fees for suppression by fire brigates and the losses as a result of breaking production and supply of electricity, gas, water and so on, nor the fees paid in relation to death and injury of people in fires are included in the calculation of fire losses.

In China the forest coverage rate is 13 percent with around 0.13 hectars per person, which is much lower than the averages in the world. However, China is one of the countries with frequent forest fires. On average over 100 people died, 600 injured and 900,000 hectars of forest are demaged annually by fire, which is about 
0.8 persent of the total forest coverage. Accordring to the survey made by the national expert group to the fireslash in the big fire of the Great Xingan mountain in 1987 the fire covered the area of 1.33 million hectars, among them 0.89 million hectars were damaged, and 23 thousands hectars became woodless. This forest conflagration burnt and distroyed large amount of forest resources as well as houses, electricity transmission grid system, bridges, tunnels, railways, various machines and equipments, which made 65 thousands people homeless. The total losses of the forest fire was about 500 million Yuan ${ }^{[1]}$.

TABLE 1. Fire Statistics in China (1988-1993)

\begin{tabular}{cccccc}
\hline \hline Year & $\begin{array}{c}\text { Number } \\
\text { of Fires }\end{array}$ & Death & Injury & $\begin{array}{c}\text { DPL } \\
\text { (Million Yuan) }\end{array}$ & $\begin{array}{c}\text { DPL/GNP } \\
(\%)\end{array}$ \\
\hline 1988 & 29852 & 2234 & 3206 & 354.24 & 0.25 \\
\hline 1989 & 24154 & 1838 & 3195 & 491.26 & 0.31 \\
\hline 1990 & 58176 & 2011 & 4897 & 523.59 & 0.30 \\
\hline 1991 & 45159 & 2049 & 3752 & 519.48 & 0.27 \\
\hline 1992 & 39391 & 1937 & 3388 & 690.25 & 0.29 \\
\hline 1993 & 38094 & 2467 & 5977 & 1120 & 0.35 \\
\hline
\end{tabular}

* GNP: Gross National Product

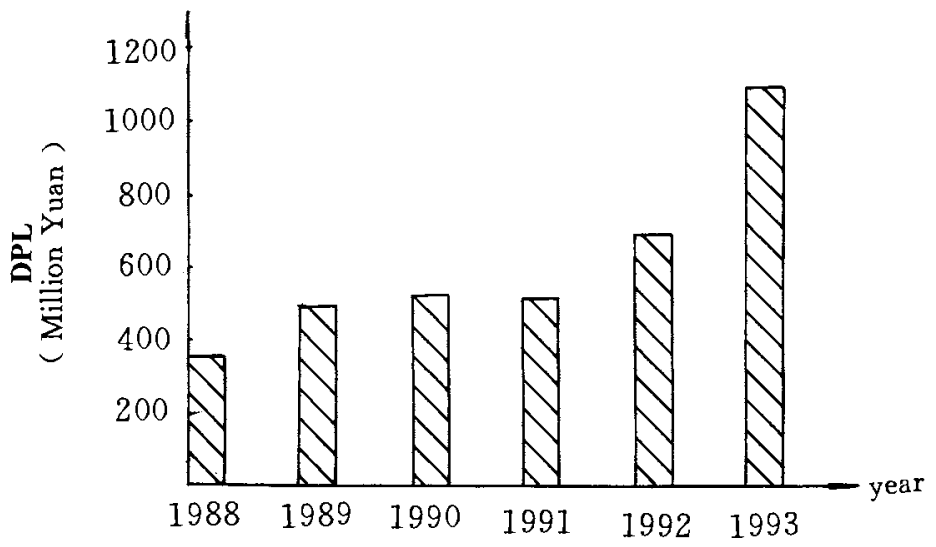

FIGURE 1. Variation of Direct Fire Losses

\section{General Structure of Fire Administration}

Fire prevention and protection are administrated by several ministries seperately 
according to the type of fire and the type of work done in the prevention and protection of fire.

The Ministry of Public Security is in charge of fire suppression and supervision of fire protection excluding forest fire. The professional fire brigates are under the Fire Protection Bureau, Ministry of Public Security.

Ministry of Forestry is responsible for the prevention and suppression of fires in forestry and forestland. The forest police troop (professional forest fire brigate) was established in 1988. The troop of ten thousands becomes the main force to attack the forest fires in the northeast and the inner Mongolia of China.

Ministry of Construction is in a position to draw up and formally issue the national codes of fire protection design.

Minisry of Labour is the respresentative of the Chinese government in labour safety including issue of the regulations related and supervision of their performance in practice. Fire safety of labour is one of the aspects covered by the labour safety.

\section{Framework of Fire Research}

A system of fire research is being establised in China, in which three categories of research are included. They are basic research, applied research and development of new technology for fire prevention and protecton. In each category there are some typical organizations.

The National Science Foundation of China (NSFC) is a government administation of funding the basic research. Fire science is a area with priority to support. The institutions under the Chinese Academy of Sciences and the universities are main bodies doing basic research. The State Key Lab of Fire Science is a representative institution of basic fire research with a national level in China. Those institutions under the Ministries mentioned in last section are the important organizations for applied research and development of new technology. Some work of developing technology and new products of fire prevention and protection is also carried out in the companies related or branches of big manufacturers.

The objective of dividing up the fire research into three categories is to make a good use of the limited funding provided by the government and raise the research level in each category. However, the problems still exist of low-level overlaping between research organizations and of transfer of research into practice.

\section{SKETCH OF ORGANIZATIONS OF FIRE RESEARCH.}

The main research institutions of fire research are outlined below respectively. The strategy and activities of funding fire research by the National Sciece Foundation of China are also introduced.

Fire Research under Ministry of Public Security. 
The Bureau of Fire Protection under the Ministry of Public Security is a leading body of professional fire brigates as well as four fire research institutes (FRI) located at cities of Tianjin, Shanghai and Shenyang and province of Sichuan respectively ${ }^{[2]}$. There are also four National Centers of Quality Control Test (NCQCT) for fire protection products concurrent to the four research institutes, which is shown in Fig. 2.

There are in total about 850 people, including 120 senior engineers and 600 engineers in those fire research institutes. Apart from the four institutes several provincial fire protection bureaux have their own fire research sections, such as in Anhui province dealing with the technical problems in local fire protection.

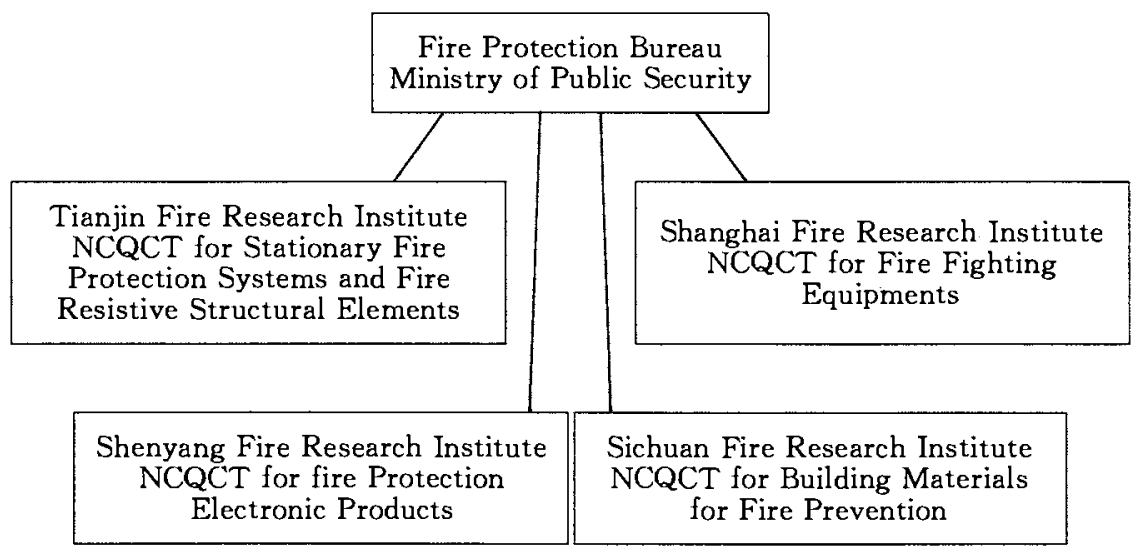

FIGURE 2. Fire Research Institutions under The Ministry of Public Security

Large - scale facilities mainly for testing and standardization have been established in the four intitutes. Among them there are a combustion hall, a furnace for fire resistance test of structural elements and a petroleum fire fighting test area in Tianjin FRI; a test facility for performance of fire fighting equipment in Shanghai FRI; a test system for electronic products of fire protection and a test facility for study of electric fire in Shenyang FRI; and a ten-story highrise building for study of smoke movement and ventilation in building in Sichuan FRI.

\section{Fire Research under Ministry of Construction}

There is a Building Fire Research Department (BFRD) under the Chinese Academy of Building Research (CABR), Ministry of Construction, which is a main body for fire research in the ministry. ${ }^{[3]}$ 
The BFRD has a fixed capital of about ten millions of Chinese Yuan, and a building about two thousands of square meters for offices and laboratory. Some facilities have been set up in the BFRD including a corn calorimeter bought from the UK, a multifunctional test furnace for structural elements and so on. The BFRD has organized a Chinese Research Society for Building Fire Prevention Technology, and has been served as a secretariat to the society since 1989 .

The typical research projects carried out in the BFRD are as follows.

- fire performances of building materials;

- fire resistance performances of building structural elements;

- intelligently controled automatic fire alarn system;

- principles and desigh methods of smoke control and exhaust system for highrise biulding.

\section{Fire Research under Ministry of Forestry}

Heilongjiang Forest Protection Research Institute is a main body of research on forest fire protection, which is located in Harbine, the local capital city of Heilongjiang province, the northeast of China. Also a Jagedaqi Center for Forest Fire Prevention in the Great Xingan mountain, Heilongjiang province was established in 1990 after a 7 - year's joint efforts of China and Canada. Furthermore, several universities and colleges under the Ministry of Forestry are involved in forest fire research, such as, the Northeast Forestry University in Harbine, Heilongiiang province, the Beijing Forestry University, the Nanjing Forestry College, the Central South Forestry College in Zhuzhou city, Hunan provrnce, and the Southwest Forestry College in Kunming city, Yunnan province.

The State Planning Commission, the Ministry of Forestry and the Provincial Government of Heilongjiang established in 1988 a special development funds of 30 million Chinese Yuan in total for 5 years for prevention and suppression of forest fire just after a very big fire in the Great Xingan mountain in May 1987. The six key projects supported by the funds are as follows: the overall design of the development funds; system for prediction, forecast and prevention of forest fire; command system for forest fire protection; serialization and standardization of forest fire fighting equipment; forest fire behavior and seperating system for fire fighting; mobile forest fire fighting equipments for big forest fires. Most of work in the projects have been completed, and well appraised by the qualified professionals in the community of fire research as well as forest fire brigates.

Fire Research under Ministry of Labour. 
It is stated in the Medium and Long Range Science and Technology Development Programm For Occupational Safety and Health (1990-2000-2020), Ministry of Labour that

- To step up basic studies in the application of science and technology for occupational safety in order to lay a solid theoretical basis for the development of science and technology in this field;

- Efforts will be devoted to research on the technology for prevention and protection of fires and explosions in the production, transportation and storage of dangerous products.

As a representative of the Chinese government in coordinating labour safety, the Ministry of Labour has funded many projects of fire safety, which have been done in institutes and universities.

\section{Activities of the NSFC on Fire Science}

National Science Foundation of China (NSFC) is a main body of coordinating and funding basic research in various areas. Fire science has been given a priority of funding since 1988 soon after the big forest fire in the Great Xingan mountain. A project entitled " present status and future prospect of basic research on fire" was entrusted to Fan Weicheng by the division of Engineering Thermophysics and Energy Utilization, the NSFC. The final report of the project was then a keynote speach in the first national symposium on fire science in 1988. It is an important step to draw attention to fire research and to accumulate the resources of funding and manpower on fire science.

Based on a successful completion of several projects on fire science a key project, headed by Fan, entitled "study of thermophysics in fire processes and fire safety" was formally approved in 1993 and started in 1994. The project is jointly funded by the NSFC, the Ministry of Forestry and the Ministry of Coal, which is the largest key project in the Division of Engineering Thermophysics and Energy Utilization during the peroid of 1991 to 1995.

Facing a rapid increase of losses and costs in fire and explosion in China, the NSFC again entrusted a review project entitled " present status and future prospects of basic research on thermal safety engineering". It aims to propose a framework of basic research on thermal safety science and engineering and to answer "why should 
it be initiated "," What to do" and "how to do it". The final report will be a solid reference for making decision in the project selection, which will further extend the area of fire science.

The NSFC encourage to make innovations in research. As a good example, the work done in the State Key Lab of Fire Science has been highly appraised by the NSFC for the contributions in bringing forth new ideas in "Computational Combustion", "Fire Seience" as well as in "Thermal Safety Science and Engnieering". All the researches mentioned above will be further supported in the future.

\section{Stake Key Lab of Fire Science (SKLFS).}

A Key Study Development Project (KSDP) was initiated in China in 1988, which was supported by the State Planning Commission through the World Bank Loan. The main objective of the KSDP is to promote research and train qualified personnel in the selected research areas by the establishment of the so-called state key laboratories in each of the areas. The State Key Laboratories should be, according to the goal, the national representative and step into the international community in their own area of research. The State Key Lab of Fire Science is one of the laboratories. The period of construction of the lab is three to four years started from July 1991.

Research orientaton of the SKLFS is study of the mechanism and rules of most aspects of fire, such as ignition, spread of fire and smoke, and suppressions. It provides techical support to engineering research and development of new technology for fire safety. The structure of the SKLFS, its function and coordinate in fire safety are given respectively in Fig 3,4 and 5 .

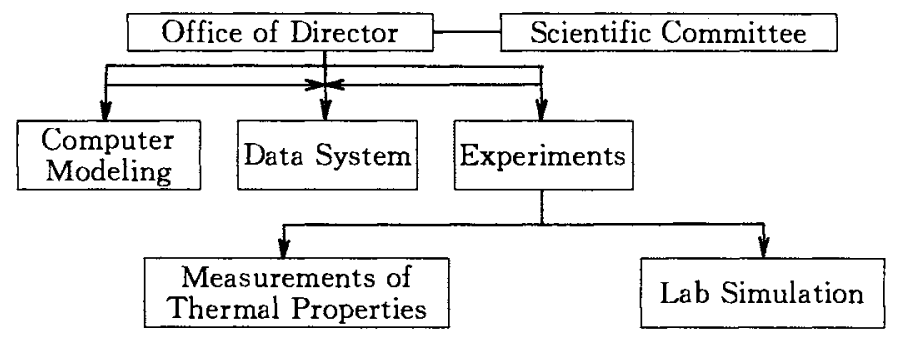

FIGURE, 3 Structure of the SKLFS 


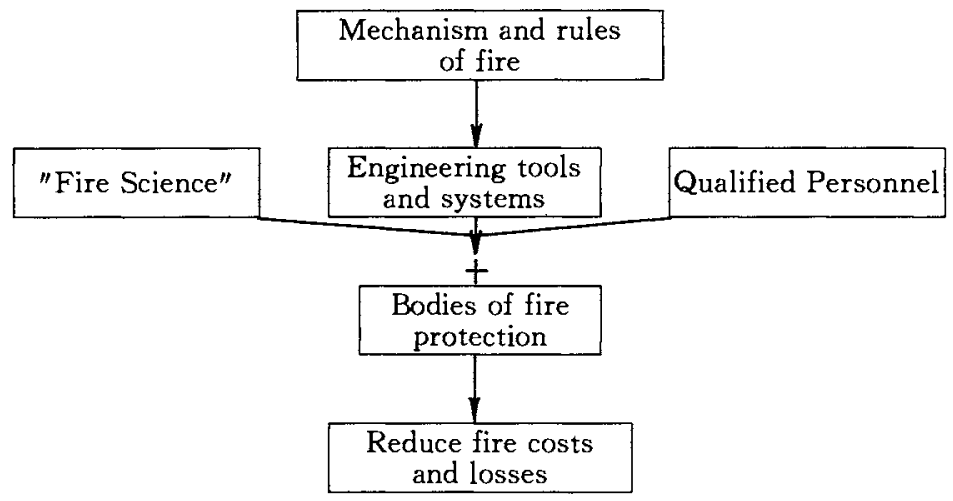

FIGURE. 4 Function of the SKLFS in fire safety

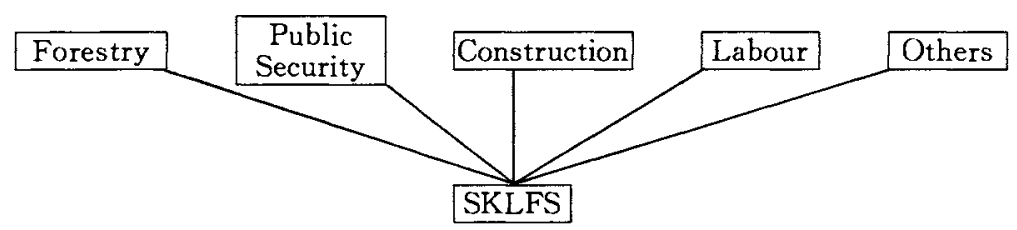

FIGURE. 5 Coordinate of the SKLFS in fire safety

Several facilities have been built to conduct experiments, such as:

- Wind tunnel with a test section of $1.8 \times 1.8 \mathrm{~m}^{2}$ and 7 meters long, in which a fuel bed can burn.

- Half scale 5 -story building

- Full scale guest room

- Thermal radiation apparatus with water curtain

- Boilover apparatus

- Furniture calorimeter

- Salty water simulation apparatus

- Several small-scale experimental setups

Apart from research, which will be introduced in the next section, many activities have been carried out in the SKLFS. Among them there are:

* first National Symposium on Fire Science was held in March 1988. 40 participants came from Ministries of Forestry, Public Security and Construction as well as Chinese Academy of Sciences and universities.

* China - Japan Joint Seminar on Fire Science was held in October 1990. 60 people attended the seminar.

* China-Japan-USSR Joint Seminar on Fire Science was held in November 
1991. There were 80 participants.

* First Asian Conference of Fire Science and Technology was held in October 1992. Over 100 participants came from 10 countries and regions. An Asian Association for Fire Science and Technology was established during the conference. Professor T. Hirano was selected as the President of the Association with its secretariat in the SKLFS.

* A Journal "Fire Safety Science" has been initiated and the first issue was published in September 1992, which is written in both Chinese and English.

* A book "Introduction to Fire Science" and many papers have been published, and several reports have been produced. Most of them are written in Chinese.

* The courses of "Fire Science" leading to both Master and Doctor degrees have been initiated in the University of Science and Technology of China.

\section{RESEARCH WORK IN THE SKLFS}

The main research projects in the State Key Lab of Fire Science are as follows.

- Forest fire behavior

- Burning rate in an enclosure

- Computer modeling of fire

- Smoke movement in a building

- Boilover of oil fire

- Fire risk analysis

Typical work done in the projects is briefly introduced below.

\section{Boilover in Oil tank fire.}

Boilover is one of the most dangerous phenomena in oil tank fires. Many works on boilover have been done in the past ${ }^{[4,5]}$, but none of them has ever attempted to study the acoustic characteristics of boilover process, and to predict the occurrence of boilover with a special noise spectrum.

A series of oil tank models with the diameter ranged from $60 \mathrm{~mm}$ to $600 \mathrm{~mm}$ were used to study the boilover with several kinds of oil as fuel, such as crude oil, kerosene, machine oil and their mixture in different proportion. The measurement system includes flame structure visualization, temperature measurement and noise recording. The signals of temperature and micro-explosion noise were digitized by a 2 - channel 12 - bit data acguisition system. The two channels can work synchronously to record the variation of temperature and noise, which makes it possible to correlate the two kinds of signal.

Many results of experiments have been obtained ${ }^{[6,7,8]}$, but only one of them is 
given here, Fig. 6, shows the temperature of oil -water layer and the microexplosion noise level in the premonitory period as a function of the burning time. A mixture of machine oil and kerosene at a volume ratio of 1 to 1 is taken as the fuel. As we can see in the figure the micro-explosion noise begins to show up when the temperature in the oil--water interface reaches the boiling point of water.

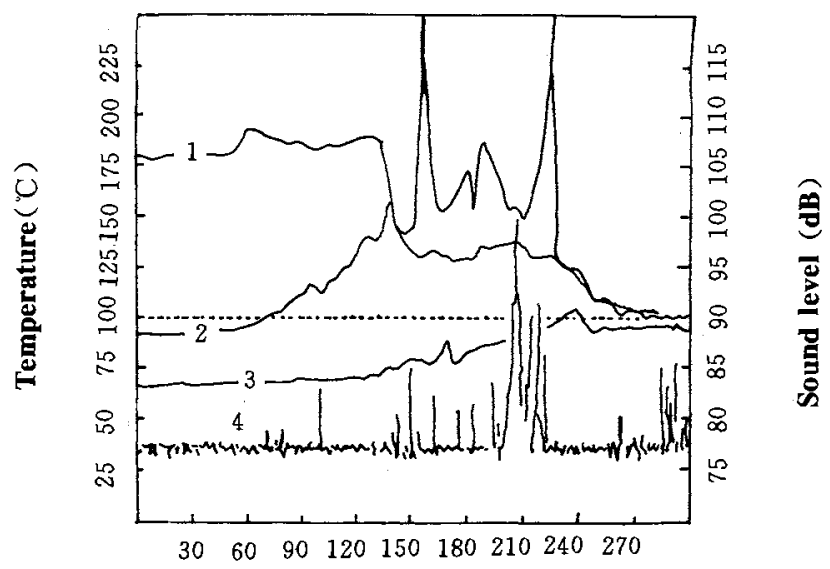

\section{Burning time (second)}

FIGURE 6. The correlation between the fuel - water temperature and the micro - explosion noise level during the premonitory and boilover happening period. Curves $1,2,3$ indicate the temperatures in oil layer, on the interface and in the water layer respectively. Curve 4 indicates the sound level of micro-explosion.

A rectangular oil container with one side wall mounted with a piece of quartz glass was designed and used for observation of the seething phenomenon in the oil water interface. It can be seen clearly that the phenomena change in the interface from no bubble generation to bubbles produced in a part of the interface, and later bubbles generated in the whole interface just before the boilover.

The experiments indicate that the combustion micro-explosion is one of the prominent premonitory phenomena of boilover, and that acoustic characteristic of the accompanied noise is closely connected with the seething status in the oil - water interface, which makes it possible to predict the occurrence of the boilover by the voice identification technique.

\section{Forest Fire Behaviour.}

Experiment study of forest fire is being done in the combustion wind tunnel, which is sketched in Fig 7. Several kinds of fuel and various velocity of incoming 

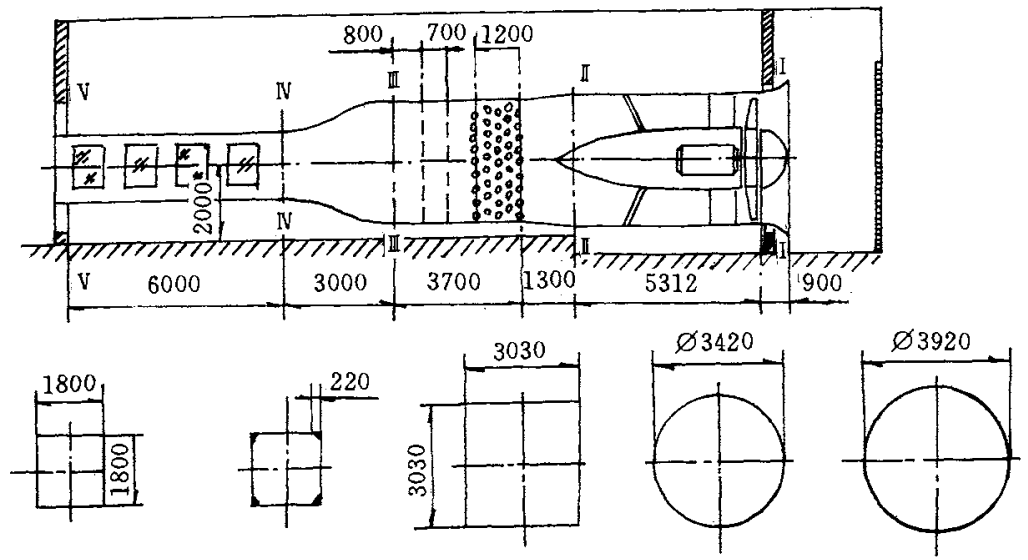

FIGURE 7. Sketch of combustion wind tunnel

flow are used to investigate the effects of fuel type and the velocity on the fire behaviour including fire spreading rate and fire intensity, which are similar to the work done in the Intermountain Fire Science Lab located in Missoula, Montana, USA. However, the influence of the pattern of incoming flow is also studied in the SKLFS. A bluff body is placed in the upstream of a fuel bed. Either Karman vortex street or a turbulent recirculation atteched to the back of the bluff body can be generated by adjustment of the size of the bluff body or the velocity of the incoming flow. Fire vortices have been observed when the Karman vortices are generated and sheded on a burning fuel bed. Furthermore, it has been found that the flame goes up along the offside of the bluff body and stays longer in the recirculation zone adjacent to the bluff body. This flame may ignite the combustibles adhered to the back surface of the bluff body, which throws a light on understanding the mechanism of transition from ground fire to crown fire in a forest fire.

\section{New Models for Building Fire}

Modeling of a fire has drawn much attention in the fire research communities. Friedman listed 62 models of building fire in $1991^{[9]}$. Generally, there are three kinds of models with regards to the methods of modeling: network modeling, zone modeling and field modeling. In network modeling a confined space in a biulding is regarded as an unit in which the state parameters of the gas are supposed to be uniform. While it is usually assumed in the zone modeling that several zones are formed in a space. Two zone model is adopted in most of studies ${ }^{[10,11]}$. Field modeling, however, can give the distributions of the state parameters in space and their changes with time in the space. ${ }^{[12,13,14,15]}$

It has been found by experiment and observation of fires that the gas layering phenomenon, which is a basic assumption of the zone modeling, is unclear in some spaces during a building fire, for example in a space of strong fire origin or with 
strong ventilation or with complicated geometry or in a large scale space. Field modeling can do better in these cases, which can predict fire processes in a space in detail. However, large capacity of computer is needed for doing so. Predictions of smoke movement and fire spread in a highrise building is not practicable in the foreseeable future. Therefore, people are thinking new models, which can be used for predictions of fire processes in a multistory or even a highrise building with a acceptable combination of accurasy and econamy. The development of the Field Zone (FZ) modeling and the Field-Zone-Network (FZN) modeling is just a kind of such attempts. ${ }^{[16,17,18]}$

The main idea of FZ modeling is to use field modeling in the spaces with fire origin, strong ventilation, complicated geometry or those fire processes which need to be understood in details, and to use zone modeling in other spaces of the building. The FZN modeling is a further development of the FZ modeling, in which the network modeling is applied in the spaces faraway from fire origin. The research being done on FZ and FZN modeling is, firstly to deal with the interfaces between the contiguous spaces with differnet models correctly, secondly to improve the numerical method, and thirdly to develop a single computer code incorporating FZ or FZN models. Only the treatment of a FZ interface is briefly descrided here as an example.

The FZ interface refers to an interface between two spaces with field and zone modeling respectively. The interface is supposed to be a kind of vent, since it is easy to treat an interface of wall type. Mass balance principle is applied in each of the control volumes along the interface to determine the velocity component $\mathrm{V}$ perpendicular to the interface. If the $\mathrm{V}$ component is positive, which means gas flowing from the field-modeling space ( $F$ space) to the zone-modeling space ( $Z$ space), the gradient of variables being solved in the field modeling across the interface is then supposed to be zero, while if the $V$ is negative, the variables take the value of the variables inside the $Z$ space. After determination of the velocity components along the interface by field modeling, the mass and energy flux through the interface can be calculated as

$$
\begin{aligned}
& \dot{\mathrm{M}}=\sum_{\mathrm{i}} p_{\mathrm{i}} \mathrm{S}_{\mathrm{i}} \mathrm{V}_{\mathrm{i}} \\
& \dot{\mathrm{H}}=\sum_{\mathrm{i}} \rho_{\mathrm{i}} \mathrm{S}_{\mathrm{i}} \mathrm{V}_{\mathrm{i}} \mathrm{C}_{\mathrm{Pi}} \mathrm{T}_{\mathrm{i}}
\end{aligned}
$$

where $p_{1} 、 T_{\mathrm{i}}$ and $\mathrm{C}_{\mathrm{P}_{i}}$ are density, temperature and specific heat of the gas respectively in the ith control volume; $S_{i}$ the surface area of the control volume, which is parallel to the interface; $V_{i}$ the velocity component perpendicular to the interface in the ith control volume.

If the calculation shows the hot gas flowing into the $Z$ space from the $F$ space, then the hot gas will entrain the surrounding air to form a hot layer in the $Z$ space, which acts as a source term in the commonly - used zone modeling equations. 
Preliminary predictions have been made of smoke movement with the FZN modeling in a five-storey building sketched in Fig. 8.

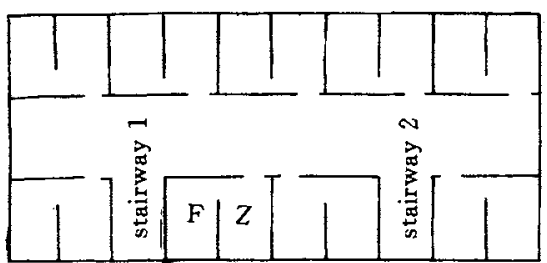

(a) Top view

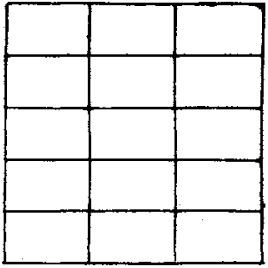

(b) Side view

FIGURE 8. Sketch of building with FZN modeling

A fire source with heat release rate of $7500 \mathrm{~W}$ and mass production rate of $0.001 \mathrm{Kg} / \mathrm{s}$ is located at the $\mathrm{F}$ room of the third floor. The power of the fire source is supposed to become two times greater in 28 second after ignition.

Predictions obtained by the FZN modeling show that the recirculating flow appears in the $F$ room, that the hot gas enters the $Z$ room through the opening from the $F$ room shortly after the fire starts and forms hot layer in the room, that then the hot layer drops below the top of the opening, and hot gas spreads into the corridor and other spaces including rooms and stairways which is studied by network modeling.

\section{Duality of Fire Rules and Its Application}

Fire rules have duality in nature: determinacy and probability. Only when we study not only its determinacy but also its probability and furthermore study their combination, can we understand the rules of fire as a whole.

The duality of fire rules can be usderstood by taking the fire occurrence as an expemple. If fuel and environment conditions are fixed, it can be determined whether a specified fire source can cause a fire with experiment and computer modeling presently available. However, as a hazard, fire always covers a wide range. The variety of human behaviour, fuel, environment condition and fire source inevitably gives rise to the uncertainties of fire occurrence. It means impossible to predict definitely whether or when or where a fire will occur. A reasonable goal of study is to provide a probability of fire occurrence and its connections with various factors.

A prime method to study the determinacy of fire is modeling including experiment and computer modeling, while statistics analysis is the main method to investigate the probability. It is being tried to construct a theoretical framework with a single software, which can accommodate various methods of modeling and 
statistics, and can combine effecs of both deterministic and probabilistic factors, and then show the duality of fire rules. The framework is so-called a Combined Modeling of Deterministic and Probabilistic Characters of Fire Rules, called the CDP modeling for short. ${ }^{[16,19]}$

The CDP modeling has a great potential of applications in fire science and engineering, which is illustrated here by a fire risk analysis of a furnished room with the modeling. As a fire goes on in the room a hazardous state will reach. We would like to know a possibility of arrival at hazard in a certain time after ignition. According to the CDP modeling the deterministic part includes heat release rate of the furniture, thermal processes in the room, and the criterion of hazard, which can all be determined by experiment and computer modeling. The probabilistic part considered in present study is ignition probability of the furniture and its arrangement, which can only be obtained by statistics usually. By combination of the two parts we will know the probability of reaching hazard at a specified fire duration.

The room studied is $4 \mathrm{~m}$ in both length and width, $3 \mathrm{~m}$ in hight. Combustible furnisheings are

$\mathrm{i}= \begin{cases}1 & \text { bed } \\ 2 & \text { table. } \\ 3 & \text { sofa }\end{cases}$

Their materials are fibers, wood and polyarethane foam. The surface area of them are $2.5,1.0$ and $1.8 \mathrm{~m}^{2}$ respectively. Three kinds of arrangement of the furnishings are considered, which affects heat release rate of the furniture. They are

$j=\left\{\begin{array}{l}\text { 1. furniture is far from all side walls of the } \\ \text { 2. furniture is near one of the side walls } \\ \text { 3. furniture is in the corners of the room. }\end{array}\right.$

Suppose that the ratio of number of people herted to the total number of people in the fire room accords with Gauss - function distribution with the fire duration as an indepentent variable. In order to determine the expression of the Gauss function we assume that a fire will hert $90 \%$ of people when temperature of hot layer reaches $473 \mathrm{~K}$ or its height is below $1.7 \mathrm{~m}$, and hert $97 \%$ of people when its temperature is $523 \mathrm{~K}$ or its height is $1.5 \mathrm{~m}$.

The fire duration for reaching the hazardous state mentioned above can be calculated by deterministic models if an ignited furnishing and its position are specified. So, in this case we can know the percentage of people herted for a certain fire duration, which is expressed by the Gauss function $\lambda_{i j}$. With use of $P_{i}$, the probability of causing fire by each of the three furnishings and $P_{i}$, the probability of each of the three furniture arrangements, which are obtainable from fire statistics, the total probability of herting people in the room fire can then be obtained by

$\mathrm{P}=\sum_{\mathrm{j}} \sum_{\mathrm{i}} \mathrm{P}_{\mathrm{j}} \mathrm{P}_{\mathrm{i}} \lambda_{\mathrm{ij}}$ 


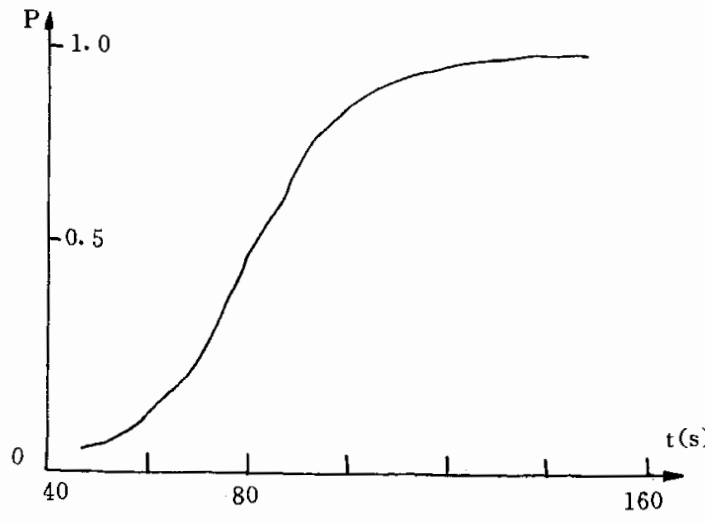

A typical curve of $P$ versus time is given in Fig. 9.

\section{Numerical Simulation of Flame Spread in Microgravity.}

The study of flames spread over solid combustibles in microgravity is essential for improve-

FIGURE 9. Total probability of hazard

(1) Flame spread with slow forced flows;

(2) Flame spread over a vertical wall in an enclosed chamber.

$\underline{\mathrm{u}_{\text {in }}=10 \mathrm{~cm} / \mathrm{s}}$

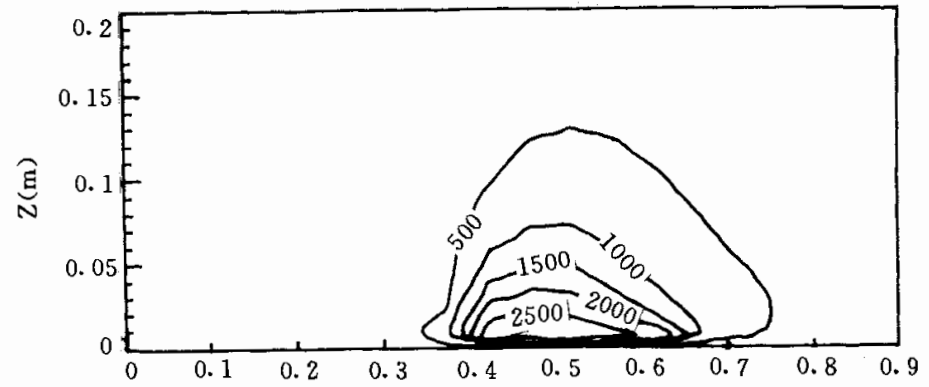

(a) 5 second

$\underline{\mathrm{u}_{\mathrm{in}}=10 \mathrm{~cm} / \mathrm{s}}$

$X(m)$

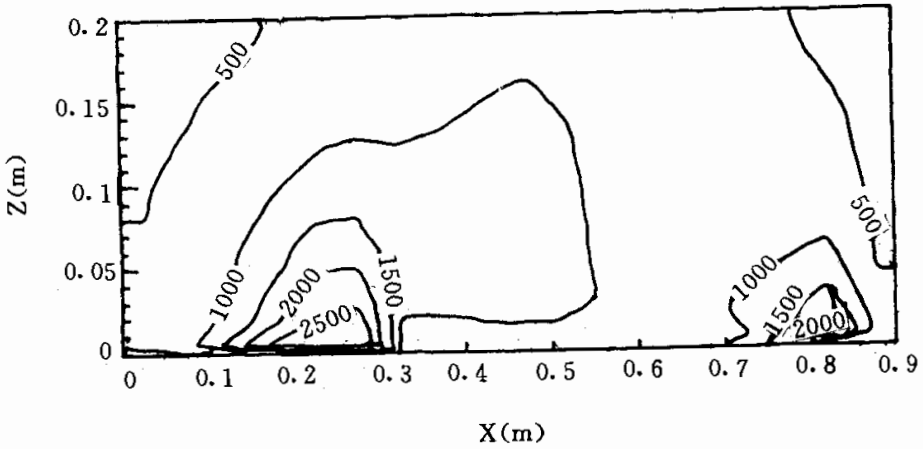

(b) 15 second

FIGURE 10. Gas - phase isotherms on $y=0.30 \mathrm{~m}$ plane at different times under $10^{-3} \mathrm{~g}$ (ignited at the location of $\mathrm{x}=0.50 \mathrm{~m}$ ) 
Models of three-dimensional, time-dependent flame spread in microgravity environment have been developed. The solid is assumed to be a thermally thin, pyrolyzing cellulosic sheet. The gas phase model includes solution of the full Navier - Stokes equations with density and pressure variations and the six-flux model of radiation heat transfer. The solid phase model consists of continuity and energy equations, the solution to which provides boundary conditions for the gas phase equations. Solid fuel pyrolysis is modeled using a first - order Arrhenius decomposition, while finite-rate chemistry in the gas phase is adopted.

The surface radiation heat losses are also included in the model. In numerical procedure, the gas - and solid-phase equations are solved separately and iteratively at each time step.

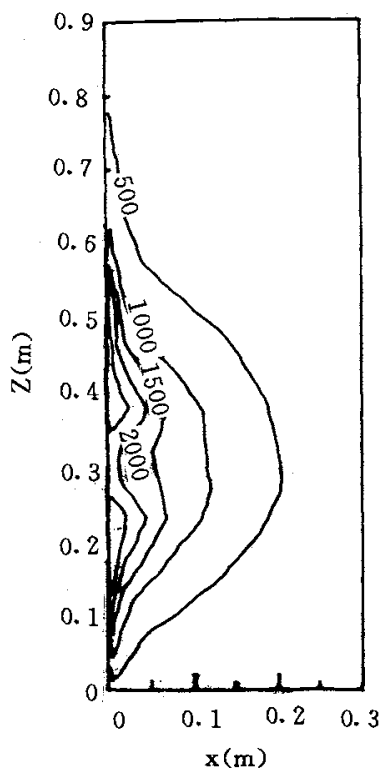

(a) isotherms

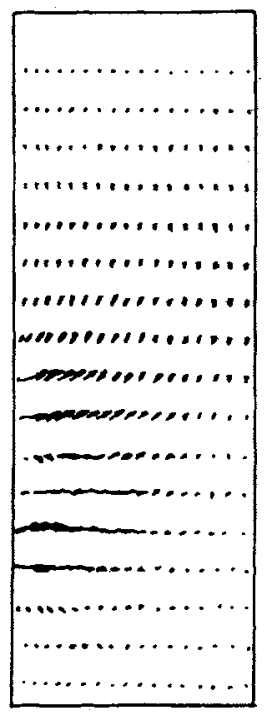

(b) velocity field $\left(\mathrm{v}_{\max }=0.345 \mathrm{~m} / \mathrm{s}\right)$

FIGURE 11. Gas - phase isotherms and velocity field on $y=0.45 \mathrm{~m}$ plane at 20 second under $10^{-4} \mathrm{~g}$ (ignited at the location of $\mathrm{z}=0.3 \mathrm{~m}$ )

The 3-D unsteady modeling of flame spread is a further development of previous models of 2-D, steady opposed - flow flame spread by West, Bhattacharjee and Altenkirch. ${ }^{[24]}$ Present predictions given in Fig. 10 show that the upstream flame spreads faster than the downstream flame at $21 \%$ oxygen with a $10 \mathrm{~cm} / \mathrm{s}$ flow.

Predictions of flame spread over a vertical wall in an enclosed chamber are 
shown in Fig. 11. It can be seen clearly the "surface fuel blowing" effect of flame spread in microgravity and the influence of the wall on the gas flow field.

\section{CONCLUDING REMARKS}

Basic research, applied research and development of technology for fire prevetion and protection are all being performed in China, which constitutes a system of research supported by State Planning Commission, State Commission of Science and Technology, State Bureau of Foreign Expert, Chinese Academy of Sciences, and National Science Foundation of China. Several Ministries such as Public Security, Labour, Forestry, Construction and so on are involved in fire research. The State Key Laboratory of Fire Science is the national representative in fire science, and acts as a joint point in the research system.

Radical changes have been initiated in fire safety from the traditional regulatory approach to fire safety engineering, which will be able to optimize in total the fire losses and costs for fire safety by applying engineering principle in most aspects of fire safety. Fire safety science is just a foundation of fire safety engineering.

China is a developing country with the largest population and fast - growing ecomamy. Reconstruction is under way in every field including fire safety. In this area technology, management, regulation, education and training as well as fire research are all needed to be enhanced. Chinese community of fire research is very much interested in joining the international community of fire safety science and engineering, and developing exchange and collaboration with the related institutions in the world.

\section{ACKNOWLEDGMENT}

Fire research in the State Key Laboratory of Fire Science has been sponsored in China by State Planning Commission, State Commission of Science and Technology, National Science Foundation, State Bureau of Foreign Expert, Chinese Academy of Sciences and University of Science and Technology of China. The authors are grateful to the colleaques in the SKLFS for their research work mentioned in this paper. Thanks are also due to Miss. Wu Jiangwei for her assistance in typing and proofreading the manuscript.

\section{REFERENCES}

1. Bi Zhongzhen, "The Prevention and Extinguishing of Forest Fire in China", Proceedings of the ' 93 Asian Fire Seminar, Science University of Tokyo, 33 $-47,1993$.

2. Chen Wengui, "The Present Situation and Development of Fire Science and Technology in China", Proceedings of the First Asian Conference on Fire Science and Technology, USTC, 26-30, 1992.

3. Li Yinqing, "Common Methods of Building Fire Designing in China ", 
Proceedings of the '93 Asian Fire Seminar, Science University of Tokyo, $139-146,1993$.

4. Arai, M. , Saito, K. and Altenkirch, R. A. , "A Study of Boilover in Liquid Pool Fires Supported on Water (I)", Combust. Science and Technology, Vol. $\underline{71}, 25-40,1990$.

5. Koseki, H. , etc. , "Experimental Study of Boilover in Crude Oil Fires", Proceedings of the third International Symposium, 865-874, 1992.

6. Liao Guangxuan, Hua Jinsong and Fa Weicheng, Experimental Study of Boilover Phenomnon in Oil Fires", Proceedings of the First Asian Conference on Fire Science and Technology, USTC, 422-432, 1992.

7. Hua Jinsong, Liao Guangxuan, Fan weicheng and Lin Hongchang, Numerical Analysis on Oil Buring on Water", The Second Asian-Pacific International Symposium on Combustion and Erergy Utilization, Beijing, P778, 1993.

8. Liu Tuanjie, Liao Guang Xuan, Fan Weicheng and Zhou Yanghui, "Study on Biolover Formatim Mechanism", The Second Asion-Pacific International Symposium on Combustion and Energy Utilization, Beijing, P773,1993.

9. Friedman, R., "Survey of Computer Models for Fire and Smoke", Factory Mutual Research Corp. , USA, 1991.

10. Cooper, L. Y., "The Development of Hazardons Conditions in Enclosures with Growing Fires", Combust. Science and Technology, Vol. 33, 279$297,1983$.

11. Cooper, L. Y. and Forey, G. P. , "The Consolidated Compartment Fire Model (CCFM) Computer Code Application", CCFM. VENTS, Parts I, II , II and N, NISTIR, Gaithersburg, MD, 1990.

12. Cox, G., "Some Recent Progress in the Field Modeling of Fire", Proceedings of the Firest Asian Conference on Fire Science and Technology, USTC, 50-59, 1992.

13. Satoh, K., "A Numerical Study of Dynamic Fire Behaviour", JSME Internation Journal, Series II, P131, 1988.

14. Fan Weicheng, Computer Modeling of Combustion Processes , Interna tional Academic Publishers and Pergamon Press, 1991.

15. Fan Weicheng, etc., Introduction to Fire Science, Publisher of Science and Technology, Hubei, 1993 (in Chinese).

16. Fan Wicheng," Some New Aspects of Computer Modeling in Fire Science ", Proceedings of the First Asian Conference on Fire Science and Technology, USTC, 39-49, 1992.

17. Fan Weicheng, Yan Zhenghua, Huo Ran, etc., "A Combined Field-Zone Model for Compartment Fire". Proceedings of the First Asian Conference on Fire Science and Technology, USTC, 300-312, 1992.

18. Fan Weicheng and Yan Zhenghua, "Towards New Models for Compartment Fire", Preceedings of '93 Asian Fire Seminar, Science University of Tokyo, 1993.

19. Fan Weicheng, Cui $\mathrm{E}$ and Chen Li, "Risk analysis of a Room Fire", Journal of China University of Science and Technology, 1994 (in Chinese accepted).

20. Bhattacharjee, S., Altenkirch, R. A., Srikantaiah, N. and 
Vedhanayagam, M. , "A Theoretical Description of Flame Spreading over Silid Combustibles in a Quiescent Environment at Zero Gravity", Combust. Science and Technology, Vol. $\underline{69}, 1-15,1990$.

21. Jiang Xi and Fan Weicheng, "Numercial Simulation of Flame Spread Over Thermally - Thin Cellulosic Sheets in Microgravity Environment", Progress in Natural Science, 1994 (in press).

22. Fan Weicheng, Yan Zhenghua and Jiang Xi, "Numerical Simulation of Fire Process in Zerogravity Environment", The Second Asian - Pacitic International Symposuim on Combustion and Energy Utilizaton, Beijing, 1993.

23. Jiang Xi and Fan Weicheng, "Numerical Simulation of Unstedy Conbustion Process in Microgravity Environment", Fire Safety Science, $\underline{3}: 1,9-17$ 1994 (in Chinese).

24. West, J., Bhattacharjee, S. and Altenkirch, R. A., "A Comparison of the Roles Played by Natural and Forced Convection in Opposed - flow Flame

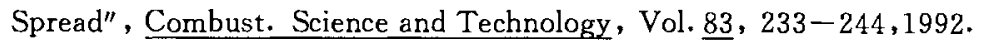


